\title{
Trends in prevalence of obesity and hypertension in an urban Congolese community
}

Bayauli MP'1,2, M'Buyamba-Kayamba $\mathrm{JR}^{1}$, Ngoyi NG ${ }^{1}$, Lepira BF ${ }^{1,3}$, Kayembe $\mathrm{KP}^{4}$, Lemogoum $\mathrm{D}^{5}$, Buila $\mathrm{MN}^{1}$, Thijs $\mathrm{L}^{6}$, Ditu $\mathrm{MS}^{2}$, Fagard $\mathrm{R}^{6}$, Degaute JP$P^{4}$, Van den Borne $\mathrm{P}^{5}$, Staessen $\mathrm{JA}^{6}$, M'Buyamba-Kabangu JR*1

${ }^{1}$ Hypertension Unit, Service of Cardiology, University of Kinshasa Hospital, the Democratic Republic of the Congo

${ }^{2}$ Division of Endocrinology and Nuclear Medicine, University of Kinshasa Hospital, the Democratic Republic of the Congo

${ }^{3}$ Service of Nephrology, Department of Internal Medicine, University of Kinshasa Hospital, the Democratic Republic of the Congo

${ }^{4}$ School of Public Health, University of Kinshasa, the Democratic Republic of the Congo

${ }^{5}$ Service of Cardiology, Erasmus Hospital, Free Brussels University, Belgium

${ }^{6}$ Studies Coordinating Centre, Department of Cardiovascular Diseases, University of Leuven, Leuven, Belgium

Received: July 2, 2017

DOI: $10.5430 /$ jer.v4n1p33
Accepted: January 25, $2018 \quad$ Online Published: February 5, 2018

URL: https://doi.org/10.5430/jer.v4n1p33

\begin{abstract}
Objective: We assessed change in the prevalence of overweight/obesity and hypertension among adult Congolese people at two different periods.

Methods: In 2007-8 the prevalence of overweight/obesity and high blood pressure was assessed among 1,292 subjects (56.6\% women) representing a random sample of the inhabitants of an urban Congolese community. The data were compared to previous observations in 424 participants (55.2\% women) obtained in a 1983-4 survey of the same community. Age structure of the two samples was different. We therefore directly standardized the prevalence of overweight/obesity and hypertension for gender and age. We modeled the risk of hypertension in a multivariable logistic regression analysis and compared the rates of awareness and control of hypertension during both periods.

Results: Crude prevalence of overweight/obesity (26.7 vs. $42.3 \% ; P<.0001)$ and hypertension $(21.5$ vs. $30.9 \% ; P=.0002)$ was higher in 2007-8. Overweight/obesity predominated among women at both periods, hypertension among men in 1983-4. Genderage directly standardized prevalence remained higher in 2007-8 for overweight/obesity [28.4(24.1-32.7)\% vs. 41.3(38.8-43.7)\%] and was borderline for hypertension [24.9(20-28.9)\% vs. 29.7(27.4-31.9)\%]. The 1983-4/2007-8 risk ratio was 0.69 for overweight/obesity $(P<.0001), 0.84$ for hypertension $(P=.054)$. Awareness, treatment and control of hypertension tended to be better in 2007-8, especially among women. The risk of hypertension in multivariable logistic analysis, was greater for male gender (OR: 1.47[95\% CI:1.14-1.88]; $P=.0029$ ), and increased with age (5.62[4.37-7.23]; $P<.0001$ ), overweight/obesity $(2.27[1.77-2.91] ; P<.0001)$ and pulse rate (for each 10 beats/min: $1.20[1.08-1.32] ; P=.0005)$; the risk was $35 \%$ higher in 2007-8 (1.35; [1.01-1.80]; $P=.0416)$.

Conclusion: Our data indicate the prevalence of overweight/obesity and hypertension has increased among adult urban Congolese people; they suggest that prevention of cardiovascular diseases might require appropriate control of these conditions.
\end{abstract}

Key Words: Overweight, Hypertension, Trends in Congolese adults

\footnotetext{
${ }^{*}$ Correspondence: M’Buyamba-Kabangu JR; Email: jerembu@yahoo.fr; Address: Hypertension Unit/Cardiology, Department of Internal Medicine, University of Kinshasa Hospital, Kinshasa 11, DR Congo.
} 


\section{INTRODUCTION}

Nearly 9.4 million deaths in the world are annually imputable to high blood pressure related disorders. ${ }^{[1]}$ Worldwide, hypertension affects over one billion people. ${ }^{[1]}$ Its prevalence in adult populations presents large variations within and between countries. ${ }^{[2]}$ Whilst in other regions, the prevalence of hypertension tends to decline since the 1980thies, an opposite trend is continuously manifest in sub-Saharan Africa. ${ }^{[3]}$ Indeed, in the high resources developed countries, early systematic detection programs, adequate treatment of elevated blood pressure and any other cardiovascular risk factor are currently implemented. Moreover, appropriate preventive measures to reduce exposition to most unhealthy lifestyles have also largely contributed to a decline in cardiac and stroke mortality during the last three decades. ${ }^{[4]}$ On the other hand, global trade and urbanization expose the developing world to lifestyle habits that favor the epidemiologic transition towards the emergence of chronic non communicable diseases. ${ }^{[4,5]}$

Available data among adult patients in the Democratic Republic of the Congo provide some evidence of increasing prevalence of overweight/obesity ${ }^{[6-8]}$ and high impact of hypertension on hospital admissions and deaths. ${ }^{[9,10]} \mathrm{Hy}-$ pertension related disorders such as congestive heart failure, chronic renal disease and stroke are increasingly reported as causes of admission and death in cities as well as in the interior of the country. ${ }^{[9,10]}$ However, it is not certain to what extent such observations in the hospital scene do effectively reflect the increment of the overall magnitude of hypertension in the community. We therefore assessed in 2007-8 the burden of cardiovascular risk factors among the inhabitants of an urban Congolese community (in the framework of the VITARAA Study: Visite de la tension artérielle et du risque associé en Afrique ${ }^{[11,12]}$ and evaluated changes in the prevalence of overweight/obesity and hypertension since a previous survey of the same community in 1983-4. ${ }^{[13,14]}$

\section{MethodS}

\subsection{Study populations}

In 2007-8, the population of the Adoula Quarter of Bandalungwa amounted to 27,860 inhabitants (14,820 women, $53.2 \%$ ) and comprised of 3,486 households (nearly 8 members per household). The quarter is located north west of Kinshasa, the main city of the Democratic Republic of the Congo. The target population of our study consisted of people aged 10 years or more $(n=17,830$ subjects; $64 \%$ of the population). We randomly selected 350 households in order to collect a $10 \%$ representative sample of the target population ( $\mathrm{n}=1,790$ people). Teams of trained observers visited the selected households at home and actually approached
1,914 subjects (e.g. $107 \%$ of the expected sample) of whom they examined 1,888 people as 26 individuals declined the invitation to participate in the study (participation rate: $98.6 \%$ ). Age and gender distribution of these subjects not enrolled were similar to those of the whole study population. However, to evaluate possible changes in the prevalence of overweight and hypertension, the present analysis only focuses on 1,292 adult participants, 731 women $(56.6 \%)$ aged 20 years or more whose data are compared to observations obtained during the period 1983-4 among 424 subjects (234 women: $55.2 \%$ ) aged $\geq 20$ years drawn from a previous $10 \%$ random sample of the inhabitants of the same community. ${ }^{[13,14]}$

\subsection{Procedures}

A calendar for household visits was elaborated taking into account availability of the heads of families. The day before scheduled visit, households were reminded and asked to refrain from caffeinated beverages and tobacco consumption the next evening. The teams of observers visited selected households two working day evenings between 6.00 and 9.00 pm from July 2007 to March 2008. They obtained demographic data and information on current smoking, alcohol intake, leisure time physical activity, weekly consumption of vegetables and fruits, medical history including awareness of hypertension and current use of medication for chronic diseases using adapted WHO STEPS questionnaire. ${ }^{[15]}$ After the subject had relaxed at least five minutes in the sitting position, the observers obtained two consecutive measurements of blood pressure and brachial pulse rate using validated OMRON M6, HEM 7001E BP monitors with appropriately sized cuff on the upper right arm. If the two records differed by $\geq 10 \mathrm{mmHg}$ a third measurement was required. In such instance only the last two readings were recorded and their average used for analysis. Every four weeks, we regularly recalibrated blood pressure monitors against a standard mercury sphygmomanometer using a T-tube and applying static pressures ranging from 0 to $200 \mathrm{mmHg}$ at $50 \mathrm{mmHg}$ intervals replacing by new machines all devices that deviated by $4 \mathrm{mmHg}$ or more. An electronic scales (Terraillon; TT100, Terraillon SAV MGF Logistique, Gennevillier, France) was used for body weight measurement to the nearest 100 grams the subject wearing loose clothing without shoes and a tape measurer for body height to the nearest centimeter. Body mass index was computed as the ratio of body weight in kilograms to the square of body height in meters.

The 1983-4 screening period lasted from December 1983 to May 1984. Teams of trained observers visited the selected household members twice at two to four weeks interval between $5.00 \mathrm{pm}$ and $8.00 \mathrm{pm}$. They obtained five consecutive blood pressure measurements on each visit using properly 
calibrated aneroid sphygmomanometers (Cuff width $14 \mathrm{~cm}$ ) secured on the right upper arm after allowing participants to relax at least five minutes in the sitting position. For current analysis, we averaged the first two blood pressure measurements recorded on the first home visit only. Pulse rate was counted over a full minute. Body weight was measured the subjects wearing usual clothing without shoes. ${ }^{[13,14]}$

Hypertension was defined as systolic pressure $\geq 140 \mathrm{mmHg}$ or diastolic pressure $\geq 90 \mathrm{mmHg}$, or use of antihypertensive drugs. Hypertension control was a blood pressure lower than $140 / 90 \mathrm{mmHg}$. Overweight/obesity was a body mass index of $25 / 30 \mathrm{~kg} / \mathrm{m}^{2}$ or higher.

\subsection{Statistical methods}

SAS software system, version 9.3 for windows (SAS Institute, Cary, NC) was used for database management and statistical analysis. As variables were normally distributed, group data were compared by use of Student $t$ test or $\chi^{2}$ test as appropriate. Because of significant difference in age structure between participants seen in 1983-4 and those examined in 2007-8, we proceeded to direct age-gender standardization of the data. Continuous variables were expressed as age-gender standardized means \pm STD, categorical variables as age-gender standardized prevalence and $95 \%$ confidence intervals. We applied stepwise logistic regression analysis with the $P$-value for independent variables to enter and stay in the model set at 0.10 given the limited sample size to model the odds of hypertension. The independent covariables considered for entry into the model were period (2007-8 vs. 1983-4), gender (female coded 0; male coded 1), age, overweight/obesity (absence coded 0 ; presence coded 1) and pulse rate. Statistical significance was a $P$ value of .05 or less on two-sided tests.

\section{Results}

Gender distribution of the participants examined in 2007-8 [731 females (56.6\%) and 561 males (43.4\%)] was similar $(P=.617)$ to that already observed in 1983-4 [234 females $(55.2 \%)$ and 190 males $(44,8 \%)]$, In comparison to $1983-$ 4 , the participants were older $(P<.0001)$ in $2007-8$ with a different gender-age distribution (see Table 1). Table 2 summarizes participants' gender-age adjusted characteristics (means \pm STD) during the two study periods and indicates higher BMI and diastolic blood pressure, but lower systolic and pulse pressure in 2007-8. Crude prevalence of overweight/obesity and hypertension significantly increased from 1983-4 to 2007-8 (see Table 3). The overall increase in the prevalence of overweight/obesity amounted to $15.6 \%$ (14.2\% for women and $16.8 \%$ for men). The increment in the prevalence of hypertension $(9.4 \%)$ was significant in women $(16.7 \%)$ not in men $(0.3 \%)$. The prevalence of overweight/obesity predominated $(P<.0001)$ among women at both periods. The prevalence of hypertension among men was higher $(P \mathrm{P}=.0007)$ in 1983-4 but tended to be lower $(P=.075)$ in $2007-8$. Table 4 shows for overweight/obesity and hypertension, the crude prevalence and the risk ratios between the two study periods in the various gender-age strata. The ratios indicate in 2007-8 a greater risk for overweight/obesity in participants $\geq 50$ years and men aged 20-29 years, and a higher risk for hypertension especially in women below 50 years. Table 5 presents the gender-age standardized prevalence of overweight/obesity and hypertension; it highlights the between period differences and risk ratios, that are illustrated in Figure 1 for overweight/obesity (left panel) and hypertension (right panel) in all participants and in various gender-age strata.
OVERWEIGHT/OBESITY

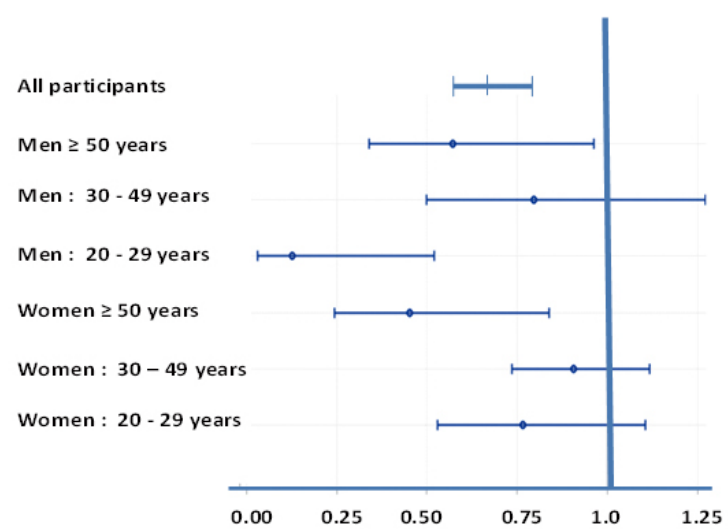

HYPERTENSION

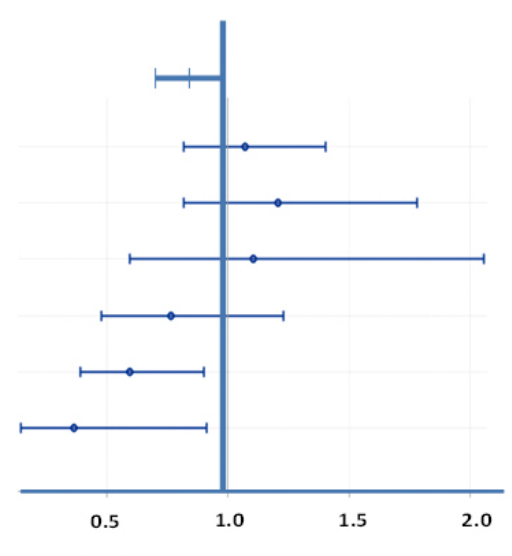

THE 1983-4 / 2007-8 RISK RATIO

Figure 1. Between period gender-age directly standardized risk ratios and $95 \%$ confident intervals for overweight/obesity (left panel) and hypertension (right panel) in all participants and crude risk ratios in the various gender-age strata 
Table 1. Participants age and gender - age strata by study period

\begin{tabular}{|c|c|c|c|c|c|c|}
\hline & \multicolumn{2}{|l|}{ Women } & \multicolumn{2}{|l|}{ Men } & \multicolumn{2}{|l|}{ Both genders } \\
\hline & 1983-4 & $2007-8$ & 1983-4 & 2007-8 & 1983-4 & 2007-8 \\
\hline $\mathbf{n}$ & 234 & 731 & 190 & 561 & 424 & 1,292 \\
\hline Age (years)* & $33 \pm 12$ & $38 \pm 15$ & $33 \pm 13$ & $37 \pm 15$ & $33 \pm 12$ & $37 \pm 15$ \\
\hline \multicolumn{7}{|l|}{ Age strata } \\
\hline $20-29$ & $118(50.4 \%)$ & $284(38.9 \%)$ & $109(57.4 \%)$ & $250(44.6 \%)$ & $227(53.5 \%)$ & $534(41.3 \%)$ \\
\hline $30-49$ & $94(40.2 \%)$ & $284(38.9 \%)$ & $45(23.7 \%)$ & $197(35.1 \%)$ & $139(32.8 \%)$ & $481(37.2 \%)$ \\
\hline$\geq 50$ & $22(9.4 \%)$ & $163(22.2 \%)$ & $36(18.9 \%)$ & $114(20.3 \%)$ & $58(13.7 \%)$ & $277(21.4 \%)$ \\
\hline
\end{tabular}

Note. Values are frequencies and percents in brackets or * means \pm STD

Table 2. Gender - age adjusted characteristics of participants by study period

\begin{tabular}{llll}
\hline \multirow{2}{*}{ Characteristic } & $\mathbf{1 9 8 3 - 4}$ & $\mathbf{2 0 0 7 - 8}$ & \multirow{2}{*}{$\boldsymbol{P}$} \\
\cline { 2 - 3 } & $\mathbf{n = 4 2 4}$ & $\mathbf{n = 1 , 2 9 2}$ & \\
\hline BMI, kg/m ${ }^{2}$ & $23.5 \pm 4.8$ & $25.0 \pm 5.2$ & $<.0001$ \\
SBP, mmHg & $130 \pm 18$ & $125 \pm 19$ & $<.0001$ \\
DBP, mmHg & $76 \pm 13$ & $79 \pm 14$ & $<.0001$ \\
PP, mmHg & $54 \pm 14$ & $46 \pm 11$ & $<.0001$ \\
Heart rate, bpm & $79 \pm 15$ & $78 \pm 14$ & .0923 \\
\hline
\end{tabular}

Note. Values are gender-age adjusted mean \pm STD. BMI: body mass index; SBP: systolic blood pressure; DBP: diastolic blood pressure; PP: pulse pressure; bpm: beats/minute.

The proportions of hypertensive patients aware of their condition (46.6\% vs. $24.2 \% ; P<.0001)$, on treatment $(29.3 \%$ vs. $9.9 \% ; P=.0001)$ and controlled $(18.3 \%$ vs. $2.2 \% ; P$ $=.0001)$ in $2007-8$ as compared to the previous period are shown in Table 6. The rates of awareness, treatment and control were similar in women and men in 1983-4; they were higher in women in 2007-8.

In the logistic model including participants from both periods (see Table 7), the risk of hypertension increased with gender (Odd ratio for men vs. women: 1.47: [95\% confident interval: $1.14-1.88$ ]; $P=.0029$ ), age (for age $\geq 45$ years: 5.62 [4.37-7.23]; $P<.0001$ ), overweight/obesity (present vs. absent; 2.27 [1.77-2.91]; $P<.0001$ ) and pulse rate (for each 10 beats/min: 1.20 [1.08-1.32]; $P=.0005)$; the risk was $35 \%$ higher in $2007-8$ compared to $1983-4$ (OR:1.35; $95 \%$ CI: [1.01-1.80]; $P=.0416)$.

Table 3. Crude prevalence of overweight/obesity and hypertension in 1983-4 and 2007-8

\begin{tabular}{lllllll}
\hline Characteristic & Women & & Men & & Both genders \\
\hline Period & $1983-4$ & $2007-8$ & $1983-4$ & $2007-8$ & $1983-4$ & $2007-8$ \\
n (\%) & $234(55.2 \%)$ & $731(56.6 \%)$ & $190(44.8 \%)$ & $561(43.4 \%)$ & 424 & 1,292 \\
Overweight/obesity & $86(36.8 \%)$ & $373(51 \%)^{* * *}$ & $27(14.2 \%)$ & $174(31 \%)^{* * *}$ & $113(26.7 \%)$ & $547(42.3 \%)^{* * *}$ \\
Hypertension & $35(15 \%)$ & $232(31.7 \%) * * *$ & $56(29.5 \%)$ & $167(29.8 \%)$ & $91(21.5 \%)$ & $399(30.9 \%) * *$ \\
\hline
\end{tabular}

Note. Values are crude prevalence (and percentage): **, *** $=P<.01$ and $P<.001$ in comparison to 1983-4.

Table 4. Crude prevalence and between period risk ratio for overweight/obesity and hypertension in various gender-age strata

\begin{tabular}{|c|c|c|c|c|c|c|}
\hline \multirow{3}{*}{$\begin{array}{l}\text { Age group } \\
\text { (years) }\end{array}$} & \multicolumn{4}{|c|}{ Crude prevalence } & \multicolumn{2}{|l|}{ Risk ratio } \\
\hline & \multicolumn{2}{|c|}{ Overweight/obesity } & \multicolumn{2}{|l|}{ Hypertension } & \multirow{2}{*}{$\begin{array}{l}\text { Overweight/obesity } \\
1983-4 / 2007-8\end{array}$} & \multirow{2}{*}{$\begin{array}{l}\text { Hypertension } \\
1983-4 / 2007-8\end{array}$} \\
\hline & $1983-4$ & $2007-8$ & $1983-4$ & 2007-8 & & \\
\hline \multicolumn{7}{|l|}{ Women } \\
\hline $20-29$ & $23.7(16.1-31.4)$ & $31(25.6-36.4)$ & $4.2(0.6-7.9)$ & $11.6(7.9-15.3)$ & $0.77(0.53-1.10)$ & $0.36(0.15-0.91)^{*}$ \\
\hline $30-49$ & $54.3(44.2-64.3)$ & $59.9(54.2-65.6)$ & $21.3(13-29.6)$ & $35.9(30.3-41.5)$ & $0.91(0.74-1.12)$ & $0.59(0.39-0.90)^{*}$ \\
\hline$\geq 50$ & $31.8(12.4-51.3)$ & $70.6(63.6-77.5)$ & $45.5(24.6-66.3)$ & $59.5(52-67)$ & $0.45(0.24-0.84)^{*}$ & $0.76(0.48-1.23)$ \\
\hline \multicolumn{7}{|l|}{ Men } \\
\hline $20-30$ & $1.8(0.0-4.4)$ & $14.4(10-18.8)$ & $11.9(5.8-18)$ & $10.8(7-14.6)$ & $0.13(0.03-0.52)^{*}$ & $1.1(0.59-2.06)$ \\
\hline $30-49$ & $31.1(17.6-44.6)$ & $39.1(32.3-45.9)$ & $42.2(27.8-56.7)$ & 35 (28.4-41.9) & $0.80(0.50-1.27)$ & $1.2(0.82-1.78)$ \\
\hline$\geq 50$ & $30.6(15.5-45.6)$ & $53.5(44.4-62.7)$ & $66.7(51.3-82.1)$ & $62.3(53.4-71.2)$ & $0.57(0.34-0.96)^{*}$ & $1.1(0.82-1.4)$ \\
\hline
\end{tabular}

${ }^{*} P<.05$ indicates a risk significantly higher in 2007-8. 
Table 5. Gender-age directly standardized prevalence and between period risk ratio for overweight/obesity and hypertension

\begin{tabular}{lllll}
\hline & Period & $\begin{array}{l}\text { Standardized } \\
\text { Prevalence (95\% CI) }\end{array}$ & $\begin{array}{l}\text { Between period } \\
\text { Risk ratio (95\% CI) }\end{array}$ & $\boldsymbol{P}$ \\
\hline $\begin{array}{l}\text { Overweight/ } \\
\text { obesity }\end{array}$ & $1983-4$ & $28.4(24.1-32.7) \%$ & $0.69(0.58-0.81)$ & $<.0001$ \\
& $2007-8$ & $41.3(38.8-43.7) \%$ & & \\
\multirow{2}{*}{ Hypertension } & $1983-4$ & $24.9(20.0-28.9) \%$ & $0.84(0.70-1.00)$ & .054 \\
& $2007-8$ & $29.7(27.4-31.9) \%$ & & \\
\hline
\end{tabular}

\section{Discussion}

The present study evaluated the change over time in the prevalence of overweight/obesity and hypertension among inhabitants of an urban Congolese community. Data obtained in 2007-8 were compared to that previously collected in 1983-4 among adult residents of the Adoula Quarter of Bandalungwa, Kinshasa. During both periods, the participants were accrued from random samples, representing $10 \%$ of the current general population of the quarter.

Table 6. Awareness, treatment and control of hypertension in 1983-4 and 2007-8

\begin{tabular}{|c|c|c|c|c|c|c|}
\hline Characteristic & Women & & Men & & Both gendeı & \\
\hline Period & $1983-4$ & $2007-8$ & $1983-4$ & $2007-8$ & 1983-4 & $2007-8$ \\
\hline n (\%) & 35 (15) & 232 (31.7) & $56(29.5)$ & 167 (29.8) & 91 (21.5) & 399 (30.9) \\
\hline $\begin{array}{l}\text { Awareness of } \\
\text { hypertension }\end{array}$ & 8 (22.9\%) & $123(53 \%)^{* * *}$ & $14(25 \%)$ & 63 (37.7\%) & $22(24.2 \%)$ & $186(46.6 \%)^{* * *}$ \\
\hline $\begin{array}{l}\text { Treatment of } \\
\text { hypertension }\end{array}$ & $2(5.7 \%)$ & $78(33.6 \%)^{* * *}$ & 7 (12.5\%) & 39 (23.4\%) & 9 (9.9\%) & $117(29.3 \%)^{* * *}$ \\
\hline $\begin{array}{l}\text { Control of } \\
\text { hypertension }\end{array}$ & 0 & $56(24.1 \%)^{* *}$ & $2(3.6 \%)$ & 17 (10.2\%) & $2(2.2 \%)$ & $73(18.3 \%)^{* * *}$ \\
\hline
\end{tabular}

Note. Values are frequencies and percents in brackets. **, *** $=P<.01$ and $P<.001$ in comparison to 1983-4.

Table 7. Independent determinants of hypertension

\begin{tabular}{llll}
\hline & Odds Ratio & $\mathbf{9 5 \% ~ C I ~}$ & $\boldsymbol{P}$ \\
\hline Period (2007-8 vs. 1983-4) & 1.35 & $1.01-1.80$ & .0416 \\
Male gender & 1.47 & $1.14-1.88$ & .0029 \\
Age $\geq 45$ years & 5.62 & $4.37-7.23$ & $<.0001$ \\
Overweight/obesity & 2.27 & $1.77-2.91$ & $<.0001$ \\
Heart rate (10 beats/min) & 1.20 & $1.08-1.32$ & .0005 \\
\hline
\end{tabular}

The salient results emphasize the concomitant increase in the prevalence of overweight/obesity and hypertension. Gender distribution of the population at both periods has remained similar with a majority proportion of women. Participants' age has increased by 4 years in 2007-8 resulting in a different gender-age demographic structure of the quarter population. However, despite direct gender-age standardization, the prevalence of overweight/obesity remained significantly higher in 2007-8; that of hypertension showed a similar trend which was significant in women only. The between periods ratios suggested an increased risk in 2007-8 that was significant for overweight/obesity and borderline for hypertension. A logistic model including participants of both periods indicates the likelihood of hypertension to be $47 \%$ higher for males, multiplied by 2.3 in the presence of overweight/obesity, by 5.6 for age $\geq 45$ years and increased by $35 \%$ in $2007-8$ as compared to $1983-4$. The latter increase ultimately providing a quantitative estimate of the trend in the prevalence of hypertension over this time period.
Whilst hypertension was virtually nonexistent in sub-Saharan Africa during the early 20th century, ${ }^{[16]}$ various population surveys have since reported a tremendous burden in this part of the world. With the exception of pockets of non acculturated and remote tribes, the prevalence of hypertension appears on the rise in the urban and even in most African rural communities. ${ }^{[3,5,17]}$ Few studies have explored the change in blood pressure level occurring among representatives of an African community following their rural-urban migration $^{[18]}$ or their enrolment into the army where their dietary salt intake got much higher. ${ }^{[19]}$ In these two instances blood pressure significantly increased. The results of the present study appear in the line of such surveys. Our work has indeed prospectively captured the changes in the prevalence of overweight/obesity and hypertension that naturally happened in a Congolese urban community over time. Unlike the two mentioned Kenyan studies, the observed changes were not linked to any properly identified phenomenon. Global trade and urbanization do expose people to unhealthy diet and lifestyle that, together with aging of populations lead to the emerging epidemiologic transition from communicable to chronic non communicable diseases. ${ }^{[4,5]}$

Population aging in our study was manifest through average age of female and male participants higher in 2007-8 than in the previous period. Such a population aging as well as the observed modification in its age structure at 24-year interval could be considered as expected features of demo- 
graphic transition and lengthening of the life expectancy. ${ }^{[4]}$ Whether any other phenomenon is underlying these observations cannot be ruled out. It is noteworthy however, that such modification accounted partly for the observed difference in the prevalence of both overweight/obesity and hypertension. The prevalence significantly augmented in function of age for all subjects and sensitivity analysis in each gender yielded similar results. The odds for hypertension were six times higher for subjects aged 45 years or older. Crude between periods difference amounted to $15.6 \%$ for the prevalence of overweight/obesity and $9.4 \%$ for hypertension. After genderage direct standardization, the difference fell to $12.9 \%$ for the prevalence of overweight/obesity, to $4.8 \%$ for hypertension. During both periods, the screening was undertaken largely within the rainy season when temperatures are rather elevated. Thus, the observed between periods differences in blood pressure levels are unlikely to be accounted for by seasonality. The systolic and pulse pressure lower in 2007-8 compared to the previous period might be in relation with the somewhat improved rate of awareness, treatment and control of hypertension. Indeed, not only were more participants aware of their hypertension in 2007-8 compared to 1983-4, a greater proportion was also treated and controlled. The rates of awareness, treatment and control among treated patients in our 2007-8 survey are interestingly of the same magnitude as those recently reported among the inhabitants of Chongqing Province in Southwest China where awareness, treatment, and control among treated patients were $44.1 \%, 36.6 \%$, and $23.3 \%$, respectively. ${ }^{[20]}$

The prevalence of overweight/obesity much elevated in 20078 translates current epidemic of obesity that affects humans worldwide and concerns the young as well as the older people. Its predominance among women during both study periods might be in relation with cultural preference, dietary habits and lack of regular physical activity in this gender. The prevalence of hypertension higher among men than women in 1983-4 was no longer so in 2007-8 and an opposite trend was even seen. At both periods, however, systolic and diastolic blood pressure increased with indices of overweight/obesity so that overweight participants had higher prevalence of hypertension than subjects with normal weight. In the presence of overweight/obesity the risk of being hypertensive was indeed multiplied by a 2.3 factor. This might therefore have favored in 2007-8 the remarkable increment in the prevalence of hypertension among women whose the obesity rate was higher. Nevertheless, the logistic model still indicated the likelihood for being hypertensive to be greater in men. Such an observation appears to be in accordance with some ${ }^{[21]}$ though not all reports. ${ }^{[22,23]}$ Middle-aged men in general do exhibit a risk of suffering from cardiovascular diseases that is two to five times greater compared to women of similar age. ${ }^{[24]}$ The risk is known to become equivalent after menopause. ${ }^{[25]}$

Finally, after adjustment for gender, age and overweight/obesity, the logistic model also showed the probability for hypertension to be majored by 35\% in 2007-8 in comparison to the previous study period. One wonders whether such an increment should not constitute the quantitative estimation of the trend in the prevalence of hypertension over the considered time period. It appears not linked to gender, to aging of the population or consecutive to overweight/obesity which are factors that often emerge as independent determinants of the prevalence of hypertension. ${ }^{[8,21,26-30]}$ No cohort of the community population has been longitudinally followed-up in the present work. We instead husked two random samples, each representative of the population during the period. Because no known catastrophic event could be advocated to explain any abrupt rise in the prevalence of hypertension, one would assume the observed change was gradual and could suppose an average of $1.46 \%$ yearly.

The lack of a longitudinal follow-up of a cohort enrolled since 1983-4 appears to be one limitation to adequate interpretation of our results. We only confronted data from two different samples albeit randomly selected. Moreover, the number of participants who were examined both in 1983-4 and in 2007-8 was very limited and did not allow a separate confrontation of their data. Likewise, the stay duration of the participants in the community was not assessed. Therefore, it cannot be excluded whether selective migration into the community was not responsible for the observed modification in the population age structure. Blood pressure monitors used at the two periods were not the same. They were regularly recalibrated as appropriate. More importantly, our data are pertaining to a particular urban quarter of the main Congolese capital city. It is uncertain whether they could be safely extrapolated to the whole country given the cultural diversity of its population.

Nonetheless, the results of our work highlight the heavy impact of excess body weight in the community. ${ }^{[27]}$ They suggest that strategies aimed at reducing obesity especially among women, might be promoted as key measures to curb the incidence of hypertension and prevent cardiovascular diseases in sub-Saharan Africa.

\section{ACKNOWLEDGEMENTS}

The authors gratefully acknowledge assistance of the Administrative Authorities of Adoula Quarter (Bandalungwa, Kinshasa). We owe gratitude to the participants for their enthusiastic participation and thank our observers for im- 
plementation of the field work. The Service of Cardiology, Erasme Hospital, Brussels Free University, Belgium, and the Belgian Hypertension Committee provided material and financial support to VITARAA study.

\section{CONFLICTS OF INTEREST Disclosure}

The author declares that there is no conflict of interest regarding the publication of this paper.

\section{REFERENCES}

[1] Lim SS, Vos T, Danaei G, et al. A comparative assessment of burden of disease and injury attributable to 67 factors and risk factors clusters in 21 regions, 1990-2010; a systematic analysis for global Burden of Disease Study 2010. Lancet. 2012; 380: 2224-60.

[2] Flack JM, Nasser SA, O'connor SM. Ethnicity and Socioeconomic Status in Hypertension. In: Izzo JL, Sica DA, Black HR, Eds. Hypertension primer. The Essentials of Blood Pressure: Basic Science, Population Science, and Clinical Management. 4th Edition, Council on High Blood Pressure Research, American Heart Association, Dallas. 2008; 276-278.

[3] Danaei G, Finucane MM, Lin JK, et al. Global Burden of Metabolic Risk Factors of Chronic Diseases Collaborating Group (Blood Pressure). National, regional and global trends in systolic blood pressure since 1980: systematic analysis of health examination surveys and epidemiological studies with 786 country-years and 5.4 million participants. Lancet. 2011; 377(9765): 568-577. https: //doi.org/10.1016/S0140-6736(10)62036-3

[4] Organisation Mondiale de la Santé. Panorama mondial de l'hypertension. Un"tueur silencieux" responsable d'une crise de santé publique mondiale. Journée mondiale de la santé 2013. Genève: Suisse, Organisation Mondiale de la Santé. 2013. p1-40.

[5] Sobngwi E, Mbanya JC, Unwin NC, et al. Exposure over the life course to an urban environment and its relation with obesity, diabetes, and hypertension in rural and urban Cameroon. International Journal of Epidemiology. 2004; 33: 769-776. PMid:15166209. https://doi.org/10.1093/ije/dyh044

[6] Bieleli E, Moswa J, Ditu M, et al. Prévalence du diabète sucré au sein de la population de Kinshasa. Congo Médical. 2000; 11: 1051-1061.

[7] Organisation Mondiale de la Santé. Enquête sur les facteurs de risque des maladies non-transmissibles à Kinshasa. Capitale de la République Démocratique du Congo, selon l'approche STEPS de l'OMS, Rapport d'analyse, Kinshasa. 2006.

[8] Katchunga PB, M'Buyamba-Kayamba JR, Masumbuko BE, et al. Hypertension artérielle chez l'adulte congolais du Sud Kivu: résultats de l'étude Vitaraa. Presse Médicale. 2011; 40: e315-e323. PMid:21376507.

[9] M'Buyamba - Kabangu JR, Biswika T, Thijs L, et al. In-hospital mortality among Black patients admitted for hypertension-related Disorders in Mbuji Mayi, Congo. Am J Hypertens. 2009; 22: 643-8. PMid:19282818. https://doi.org/10.1038/ajh. 2009.47

[10] Tambwe MJ, Mbala Mukendi M, Dikassa LN, et al. Morbidity and mortality in hospitalized Zairian adults. South African Medical Journal. 1995; 85: 74. PMid:7597537.

[11] Bayauli MP, M'Buyamba-Kayamba JR, Lemogoum D, et al. Prehypertension, Hypertension and Associated Cardiovascular Risk Factors among Adult Congolese Urban Dwellers: Results of the Vitaraa Study. World Journal of Cardiovascular Diseases. 2014; 4: 390-398. https://doi.org/10.4236/wjcd.2014.48049

[12] Bayauli MP, M'Buyamba-Kayamba JR, Lemogoum D, et al. Cardiovascular risk factors among the inhabitants of an urban Congolese community: results of the VITARAA Study. IJC Metabolic \& En- docrine. 2014; 4: 33-38. https://doi.org/10.1016/j.ijcme. 2014.07 .003

[13] M'Buyamba-Kabangu JR, Fagard R, Staessen J, et al. Correlates of blood pressure in rural and urban Zaïre. Journal of Hypertension. 1987; 5: 371-375. https://doi.org/10.1097/00004872-198 706000-00018

[14] M'Buyamba-Kabangu JR, Fagard R, Lijnen P, et al. Epidemiological study of blood pressure and hypertension in a sample of urban Bantu of Zaire. Journal of Hypertension. 1986; 4: 485-491. https://doi.org/10.1097/00004872-198608000-00015

[15] Bonita R, de Courten M, Dweyer T, et al. Surveillance of risk factors for non communicable diseases: the WHO STEPwise approach; 2001 [Summary, Geneva]

[16] Donnison C. Blood pressure in the African natives: its bearing upon aetiology of hyperpiesa and arteriosclerosis. Lancet. 1929; 1: 6-7. https : //doi .org/10.1016/S0140-6736 (00) 49248-2

[17] Campbell NR, Lemogoum D. Hypertension in sub-Saharan Africa: a massive and increasing health disaster awaiting solution. Cardiovasc J Afr. 2015; 26(4): 152-154. PMid:26407216.

[18] Poulter NR, Khaw KT, Hopwood BEC, et al. The Kenyan Luo migration study: Observations on the initiation of a rise in blood pressure. British Medical Journal. 1990; 300: 967-972. PMid:2344502. https://doi.org/10.1136/bmj .300.6730.967

[19] Shaper AG. Cardiovascular disease in the tropics-3: Blood pressure and hypertension. British Medical Journal. 1972; 3(5830): 805-807. https://doi.org/10.1136/bmj.3.5830.805

[20] Liu XL, Gu W, Li ZL, et al. Hypertension prevalence, awareness, treatment, control, and associated factors in Southwest China: an update. Journal of Hypertension. 2016. https ://doi .org/10.1 097/HJH.0000000000001203

[21] Erem C, Hacihasanoglu A, Kocak M, et al. Prevalence of prehypertension and hypertension and associated risk factors among Turkish adults: Trabzon Hypertension Study. Journal of Public Health. 2008; 31(1): 47-58. PMid:18829520. https://doi.org/10.1093/pu bmed/fdn078

[22] Lai SW, Li TC, Lin CC, et al. Hypertension and its related factors in Taiwanese elderly people. Yale J Biol Med. 2001; 74(2): 89-94. PMid:11393265.

[23] Önal AE, Erbil S, Özel S, et al. The prevalence of and risk factors for hypertension in adults living in Istambul. Blood Pressure. 2004; 13 : 31-36. https://doi.org/10.1080/08037050410025762

[24] Jousilahti P, Vartiainen E, Tuomilehto S, et al. Sex, Age, Cardiovascular Risk Factors, and Coronary Heart Disease: A Prospective Follow-Up Study of 14786 Middle-Aged Men and Women in Finland. Circulation. 1999; 99(9): 1165-1172. https://doi.org/10 .1161/01.CIR.99.9.1165

[25] Wilson PWF, D'Agostino RB, Levy D, et al. Prediction of Coronary Heart Disease Using Risk Factor Categories. Circulation. 1998; 97(18): 1837-1847. https://doi.org/10.1161/01.CIR. 97.18 .1837

Published by Sciedu Press 
[26] Seedat YK, Reddy J. The clinical pattern of hypertension in the South African black population: a study of 1000 patients. African Journal of Medicine and Medical Sciences. 1976; 5: 1-7. PMid:829699.

[27] Kodama S, Horikawa C, Fujihara K, et al. Comparisons of the strength of associations with future type 2 diabetes risk among anthropometric obesity indicators, including waist-to-height ratio: a metaanalysis. American Journal of Epidemiology. 2012; 176(11): 959969. PMid:23144362. https://doi .org/10.1093/aje/kws172
[28] Opie Lh, Seedat YK. Hypertension in subSaharan Afrcan populations. Circulation. 2005; 112: 3562-3568. PMid:16330697.

[29] Addo J, Smeeth L, Leon DA. Hypertension in sub-Saharan Africa: a systematic review. Hypertension. 2007; 50: 1012-8. PMid:17954720. https://doi.org/10.1161/HYPERTENSIONAHA.107.093336

[30] Kearney PM, Whelton M, Reynolds K. Global burden of hypertension: analysis of worldwide data. Lancet. 2005; 365: 217-23. https://doi.org/10.1016/S0140-6736(05)70151-3 